\title{
MODALIDADES DE ACTUACIÓN DE LOS PROFESIONALES DE LA EDUCACIÓN EN EL CAMPO DE LO SOCIAL
}

\author{
IMPLEMENTATION PROCEDURES OF EDUCATION PROFESSIONAL IN THE SOCIAL FIELD
}

\author{
ENRIQUETA MOLINA RUIZ1; SUSANA CARBONELL BUSTOS \\ Universidad de Granada (España)
}

\section{RESUMEN}

Mostramos un aspecto parcial del estudio vinculado a un Proyecto de Innovación² dirigido a orientar a los estudiantes de Pedagogía sobre salidas profesionales. Se instala en el marco general representado por el componente formativo que supone el Practicum. Éste, es entendido como plataforma de formación que permitirá conocer los diferentes ámbitos donde ejercer la profesión y, en ellos, las diferentes "modalidades" existentes. De los varios ámbitos en que los pedagogos pueden intervenir, nos centramos en el social y, concretamente, en el campo de colectivos desfavorecidos necesitados de desarrollo y protección social, siendo nuestro objetivo mostrar información precisa sobre las diferentes modalidades de actuación existentes al respecto en nuestro contexto. La metodología de investigación de la que derivan los resultados es de tipo cualitativa. Las fuentes de las que obtendremos información vienen representadas por los "organismos que determinan la política de intervención social" a nivel regional. Apoyamos la recogida de datos en "documentos institucionales" elaborados desde dichos organismos. Aplicamos el procedimiento "análisis de contenido" en el tratamiento y reducción de los datos. Situamos la aportación en una primera fase del estudio dirigida a localizar las posibilidades de intervención de los profesionales de la educación en general, tratando de descubrir, a partir de ellas, las específicas de pedagogos. Los resultados muestran las diferentes modalidades de actuación educativa en los sectores representados por: "Servicios Sociales e Inclusión", "Drogodependencia", "Personas Mayores", "Infancia y Familias", "Personas con Discapacidad" y "Atención a la Dependencia", precisando características, condiciones, actuaciones, competencias exigidas al profesional, etc. que orientarán la acción de los estudiantes en prácticas y permitirá obtener una visión global del campo profesional.

Palabras clave: Formación inicial. Practicum. Intervención Social.

\begin{abstract}
We show one aspect of the study linked to an innovation project (2) aimed at guiding students on careers Pedagogy. It is installed in the general framework represented by the training component representing the Practicum. This is understood as training platform that will reveal the different areas where the profession and, in them, the different "modalities" exist. Of the several areas in which educators can intervene, we focus on the social and specifically in the field of disadvantaged groups in need of development and social protection, and our objective is to show accurate information about the various forms of existing performance about our context. The research methodology of deriving the results is qualitative type. The sources from which we obtain information are represented by "agencies that determine social policy intervention" at the

\footnotetext{
${ }^{1}$ Corresponding author: Enriqueta Molina Ruiz. E-mail: emolina@ugr.es

2 "Implicación activa de los estudiantes en el descubrimiento y conocimiento de sus salidas profesionales y su futuro laboral" subvencionado por la Universidad de Granada (Vicerrectorado de Ordenación Académica y Profesorado, Unidad de Innovación Docente).
} 
regional level. We support the collection of data on "corporate documents" produced from such organisms. We apply the procedure "content analysis" in the treatment and data reduction. We place the contribution in a first phase of the study aimed to find the possibilities of intervention of professional education in general, trying to discover from them, the specific teachers. The results show the different types of educational activities in the sectors represented by: "Social Services and Inclusion", "Substance Abuse", "Elderly", "Children and Families", "Persons with Disabilities" and "Care Unit" specifying characteristics, conditions, actions, required professional skills, etc. to guide the action of the trainees and enable you to get an overview of the professional field.

Key words: Initial training. Practicum. Social Intervention 


\section{Introducción}

El presente trabajo constituye una aportación enmarcada en el campo de la formación y de la orientación profesional universitaria, todo ello, integrado en el contexto más amplio representado por el Practicum. Se dirige a averiguar ámbitos de actuación de los profesionales de la educación en el área de la acción social, necesitados de desarrollo. Pretendemos conocer nuevos contextos de actuación, en los que nuestros estudiantes, realizando sus prácticas profesionales, puedan acercarse a la realidad social y conociendo de cerca su problemática, adquirir una rica formación al tiempo que prestar un servicio a la sociedad.

Se viene demandando a la Universidad mayor implicación ante los nuevos problemas enfrentados por la sociedad. Así, el informe de la Global University Network for Innovation (2009) "La Educación Superior en el Mundo: Nuevos Retos y Roles Emergentes para el Desarrollo Humano y Social" plantea como objetivos "repensar y proponer nuevas vías para el intercambio de valor entre las instituciones de educación superior y la sociedad". Expone funciones básicas de la Universidad junto a "roles emergentes" o nuevos retos en el contexto de la globalización críticos para el papel de la educación superior ante el desarrollo humano y social: implicaciones sociales y ambientales de la ciencia y la tecnología, convivencia multicultural, educación para la paz, ciudadanía global, ética y valores.

Cabe pensar que, ante tales retos, el campo educativo deberá ampliar su radio de acción y exigir a sus profesionales mayor dinamismo para intervenir en contextos distintos a la enseñanza reglada. Entendemos que el practicum podría ser el medio idóneo para clarificar y definir la actuación de los profesionales de la educación.

La formación recibida a través del practicum es altamente valorada, siendo varios los estudios (Grootenboer, 2006; Kay \& Rangel, 2009) que presentan resultados en que los estudiantes informaron haber desarrollado competencias profesionales específicas durante el practicum reconociéndole múltiples beneficios: hace posible una mezcla eficaz de teoría y práctica; ofrece oportunidad de desarrollar conocimientos y habilidades en contextos de trabajo; las experiencias vividas ayudan a configurar el conocimiento de exigencias y competencias de la profesión, etc.

Sin duda, el potencial de los futuros profesionales para actuar y reflexionar, se verá influido positivamente por las oportunidades que los programas de formación ofrezcan a partir de las teorías aplicadas (Fung, 2005). Situados en el ámbito social, entendemos especialmente adecuado el modelo "Aprendizaje-Servicio" (Vickers, Harris \& McCarthy, 2004; Wetig, 2006; Kelley, Hart \& King, 2007) porque:

$\checkmark$ Tiende a corregir las tradicionales aplicaciones de practicum centradas, por lo general, en perfeccionar las habilidades de los aprendices sin responder a las necesidades de los lugares de prácticas:

$\checkmark$ Las actuaciones y los espacios se amplían, brindando a los futuros profesionales la oportunidad de convertirse en ciudadanos activos comprometiéndose en los escenarios más amplios que constituye la comunidad local;

$\checkmark$ Se considera vía que permite desarrollar relaciones simbióticas significativas entre universidad y comunidad y entre futuros profesionales y comunidad local;

$\checkmark$ Sus diferentes fórmulas constituyen experiencias que proporcionan oportunidades de comprometerse activamente en la construcción de pedagogías dirigidas a traducir eficazmente las creencias dentro de prácticas sólidas.

$\checkmark$ Representa un "tercer espacio" de interacción donde los requisitos del programa de formación y las necesidades de los sujetos atendidos en los diferentes escenarios de prácticas, deben converger.

De acuerdo con Zeichner (2010) las universidades deben crear vínculos directos con experiencias de trabajo y programas de formación valorando tanto al profesorado como al personal que trabaja de manera ejemplar en espacios híbridos o "tercer espacio". 


\section{Finalidad y objetivos de estudio}

\section{Finalidad}

Ofrecer a los futuros profesionales de la educación, una formación que les prepare para realizar intervenciones adecuadas dirigidas al desarrollo, en los diferentes contextos de intervención social.

\section{Objetivos}

Averiguar las diferentes modalidades de actuación en el ámbito de la acción social en instituciones oficiales centradas en sectores necesitados de desarrollo. Proporcionar información facilitadora del conocimiento de los aspectos esenciales definitorios de los contextos de prácticas situados en el campo de la acción social necesitados de desarrollo.

\section{Metodología}

Sujetos participantes

El estudio, se hará extensivo a las instituciones oficiales -organismos y unidades organizativas- en el campo de la protección social que, a nivel regional, dicten la política de intervención social que contemplen acciones educativo-formativas.

\section{Recogida de datos}

Apoyamos la recogida de datos en los "documentos institucionales" elaborados desde los organismos oficiales en el campo de la acción social, constituidos por las páginas web que muestran las diversas modalidades, sus programas, acciones, etc. Así, mismo, analizamos los documentos representados por la normativa oficial de carácter legislativo que ayuden a definir y precisar las características y actuaciones que estudiamos.

\section{Análisis de los datos}

El análisis de la información se realizará a través de "análisis de contenido" (Krippendorf, 1990; Kerlinger, 2001; Sandín, 2003) aplicando en la revisión de los documentos e interpretación de los resultados el método comparativo constante (Glasser y Straus, 1999; Corbin, 2010).

\section{Resultados}

Presentamos los hallazgos relativos a nivel regional -representado en España por las diferentes autonomías-, situándonos en la Comunidad Autónoma de "Andalucia". En ella, la institución en la que se organiza políticamente el autogobierno es la Junta de Andalucía (2015a) que cuenta con 13 departamentos o Consejerías. De éstas, nos centramos en la de "Igualdad y Políticas Sociales" (Tabla 1) que se estructura en varias Secretarías Generales siendo el objeto de nuestro estudio la de Políticas Sociales con sus tres Direcciones Generales de: 1) Servicios Sociales y Atención a las Drogodependencias; 2) Personas Mayores, Infancia y Familias y 3) Personas con Discapacidad. 
Modalidades de actuación de los profesionales de la educación en el campo de lo social

Tabla 1. Áreas de Acción Social a nivel autonómico

\begin{tabular}{|c|c|c|}
\hline \multicolumn{3}{|c|}{ JUNTA DE ANDALUCÍA } \\
\hline \multicolumn{3}{|c|}{ CONSEJERÍA DE IGUALDAD Y POLITICAS SOCIALES } \\
\hline \multicolumn{3}{|c|}{ SECRETARÍA GENERAL DE POLÍTICAS SOCIALES } \\
\hline $\begin{array}{l}\text { Servicios Sociales y Atención a las } \\
\text { Drogodependencias }\end{array}$ & \begin{tabular}{|l|l} 
Personas Mayores, Infancia y \\
$\underline{\text { Familias }}$
\end{tabular} & $\frac{\text { Personas con }}{\text { Discapacidad }}$ \\
\hline \multicolumn{3}{|c|}{ ÁREAS DE ACTIVIDAD: } \\
\hline Servicios Sociales e Inclusión & $\begin{array}{l}\text { Comunidad gitana } \\
\text { Movimientos migratorios } \\
\text { Servicios sociales comunitarios } \\
\text { Voluntariado social } \\
\text { Zonas de transformación social }\end{array}$ & \\
\hline Drogodependencia & $\begin{array}{l}\text { Atención sociosanitaria a la drogodependen } \\
\text { Incorporación social } \\
\text { Prevención de la drogodependencia } \\
\text { Información, formación e investigación } \\
\text { Guías, manuales, estudios y otros documen } \\
\text { Observatorio Andaluz sobre Drogas y Adicci }\end{array}$ & \\
\hline Personas Mayores & Envejecimiento activo & \\
\hline Infancia y Familias & $\begin{array}{l}\text { Atención a infancia y adolescencia } \\
\text { Apoyo a la familia } \\
\text { Registro de mediación familiar } \\
\text { Separación de la familia biológica y atención } \\
\text { Acogimiento familiar y Adopción } \\
\text { Programa + } 18 \\
\text { Atención a menores inmigrantes }\end{array}$ & \\
\hline Personas con Discapacidad & $\begin{array}{l}\text { Centros de Valoración y Orientación } \\
\text { Servicios y prestaciones para personas con }\end{array}$ & acidad \\
\hline Atención a la Dependencia & $\begin{array}{l}\text { Catálogo de prestaciones } \\
\text { Recursos didácticos } \\
\text { Plan de formación }\end{array}$ & \\
\hline
\end{tabular}

Varias son las áreas de actividad que se desarrollan a partir de las tres Direcciones Generales, de ellas, nos centramos en las que consideramos tienen mayor relación con aspectos educativos y de formación, temas éstos, representativos de la profesión de los profesionales de la educación y, que situamos en la columna de la izquierda. 
Las políticas sociales en las diferentes áreas van dirigidas a varios sectores. De ellos, seleccionamos los de mayor vinculación con el campo profesional estudiado, situándolos en la columna de la derecha procediendo a presentarlos a continuación.

\section{Servicios Sociales e Inclusión}

En esta área (Figura 1), la acción de los profesionales de la educación está plenamente justificada en las actuaciones dirigidas a la "Comunidad Gitana". Esta afirmación la apoyamos en declaraciones expresadas en los objetivos del Plan Integral para la Comunidad Gitana de Andalucía (PICGA), aprobado en 1997 y prorrogado hasta la elaboración de uno nuevo (Junta de Andalucía, 1997 y 2015b) al indicar que: 1) se propone "... la promoción integral..." (objetivo a) por considerar que uno de los principales factores para lograrlo es la educación; 2) habrá que contar con varias organizaciones entre las que se señalan las "educativas" (objetivo c). Así mismo, de las diferentes áreas de actuación que detallan (Vivienda, Salud, Cultura, Acción Social, Mujer, Educación, Formación y Empleo) la "educación" y la "formación" están presentes en todas ellas, exceptuando las dos primeras. Destacamos, por su importancia en nuestro campo, las actuaciones asignadas a las áreas de "Educación" y "Formación y Empleo" procediendo a organizarlas en torno a las temáticas a las que hacen referencia.

Actuaciones en el área de Educación:

\section{Enseñanza básica}

- Escolarización previa y continuada de la población infantil gitana en el nivel obligatorio.

- Posibilitar que los jóvenes completen los estudios de los niveles obligatorios de la enseñanza. Colaboración con la Comunidad

- Colaboración entre sectores de la comunidad escolar y equipos de acción social como apoyo familiar y seguimiento de la escolarización ya iniciada.

Recursos educativos

- Refuerzo de los recursos educativos, con la existencia de residencias escolares abiertas.

- Incluir en el material didáctico escolar información positiva sobre la minoría étnica gitana y elaborar materiales específicos sobre su cultura.

Acción con las familias:

- Facilitar información y asesoramiento a familias económicamente desfavorecidas de la comunidad gitana sobre las ayudas del sistema educativo.

- Fomentar la incorporación de los padres de escolares gitanos a órganos colegiados y AMPAs.

- Mostrar a familias gitanas ventajas de obtener las titulaciones académicas medias y superiores. Alfabetización

- Programas de alfabetización adaptados a las características propias de su cultura.

- Desarrollar el proceso de alfabetización en respuesta a necesidad específica del pueblo gitano

- Aprovechar cualquier actuación formativa con gitanos para introducir la alfabetización de adultos. Integración cultural

- Fomentar proyectos pedagógicos de los centros para integración cultural de la población gitana.

- Promover actividades no regladas abiertas a la convivencia pluricultural en escuelas de elevada población infantil gitana

Formación profesional

- Formación profesional mínima de la población gitana (18-21 años) que no logró titulación básica Formación Profesorado:

- Fomento del estudio de la cultura gitana en la formación del profesorado.

- Colaborar en la realización de cursos de formación para profesores de personas adultas gitanas. Actuaciones en el Área de Formación y Empleo:

- Ofertar Programas de Formación que capaciten para ejercer una actividad adecuada.

- Diseño de talleres iniciales para jóvenes que no hayan completado la ESO.

- Establecer cauces de información que lleve a conocer los derechos y deberes laborales. 
- Fomentar su acceso a las distintas modalidades del mercado de trabajo, a través de programas de fomento del empleo, potenciando la economía social como alternativa de empleo no marginal.

- Revisar normativa de venta ambulante y adaptarla a necesidades reales de la población gitana

- Intensificar los programas sociales en zonas de acogida de trabajadores agrícolas de temporada.

\begin{tabular}{|c|c|}
\hline Servicios Sociales e Inclusión $\Rightarrow$ & $\begin{array}{l}\text { Comunidad gitana } \\
\text { Movimientos migratorios } \\
\text { Sorvicios sociales comunitarios } \\
\text { Voluntariado social } \\
\text { Zonas de transformación social }\end{array}$ \\
\hline
\end{tabular}

Figura 1. Campos de acción del Área de Servicios Sociales e Inclusión

De igual modo entendemos que en el sector "Movimiento Migratorio", la acción del profesional pedagogo está claramente justificada por hallar alusión al factor educativo y formativo en los objetivos generales del II Plan Integral para la Inmigración en Andalucía (Junta de Andalucía, 2006). En relación al factor educativo, al asegurar el acceso de los inmigrantes a los servicios básicos comunes, entre los que se encuentra la educación (punto 3), en relación al factor formativo, al especificar la necesidad de "Diseñar y promover programas de formación para todas las personas que realicen actividades, en el ámbito privado o público, permitiendo una adecuación constante a la aplicación de conocimientos" (punto 6).

Se estructura en diversas áreas de actuación (1. socio-educativa; 2. formación; 3. cultura, ocio y participación; 4. investigación; 5. sensibilización social; 6. cooperación al desarrollo; 7. socio-laboral; 8. recursos sociales y bienestar social; 9 . equipamiento, alojamiento y vivienda; 10 . socio-sanitaria; 11. atención jurídica) de las que podríamos afirmar que en la gran mayoría, el factor educativo y de formación están presentes, así ocurre, sobre todo, con las siete primeras. Los objetivos específicos y las medidas para su logro han sido establecidos por la Dirección General de Servicios Sociales e Inclusión (Junta de Andalucia, 2007).

En la actualidad, el III Plan Integral para la Inmigración en Andalucía Horizonte 2016 (Junta de Andalucía, 2014) constituye otro paso hacia una sociedad más cohesionada. Entre sus objetivos dirigidos a promover la plena integración social, económica, laboral y cultural de las personas inmigrantes, están presentes con fuerza: a) la "educación" como servicio básico al que podrán acceder en condiciones de igualdad; b) la actividad "investigadora" de calidad que, difundiendo el conocimiento disponible, mejore las actuaciones; y d) la "formación", diseñando y promoviendo programas, actividades todas ellas, específicas y caracterizadoras de la actuación del profesional pedagogo.

En el sector representado por los Servicios Sociales Comunitarios (Junta de Andalucía, 2015c) orientados a obtener mayor bienestar social y calidad de vida de la población andaluza, así como a prevenir y eliminar la marginación, el pedagogo podría desempeñar sus funciones en las tres modalidades en que se articulan:

1. Centros de Servicios Sociales Comunitarios. Constituyen la infraestructura básica para la prestación de servicios sociales en una zona de trabajo social. En ellos, de las tres unidades básicas comunes (Dirección, Unidad Administrativa y Equipo de Intervención) la tercera representa un nicho profesional por excelencia. El personal de este Equipo realiza las tareas necesarias para el desarrollo de las prestaciones básicas del sistema público de servicios sociales debiendo poseer "con carácter preferente la titulación de Trabajo Social, Psicología, Educación Social u otras equivalentes" entre las que entendemos se hallan situados los estudios de Pedagogía. 
2. Centros Sociales Polivalentes. Como equipamiento complementario a los anteriores, están destinados a prestar o facilitar a la comunidad la realización de acciones o programas de contenido social, como talleres, cursos, reuniones y actividades similares.

3. Albergues o Centros de Acogida. Establecimiento residencial de carácter temporal, destinado a acoger al colectivo de personas en estado de necesidad social, facilitando medios adecuados para normalizar su convivencia y procurando la necesaria intervención para su inserción social.

Los servicios que se prestan desde los Servicios Sociales Comunitarios son los de Información, valoración, orientación y asesoramiento; Convivencia y reinserción social; Cooperación social; Ayuda a domicilio; y Prestaciones complementarias. De ellos, los tres primeros representan diferentes situaciones de actuación para los profesionales de la educación. El de Convivencia y reinserción social supone la búsqueda de alternativas al internamiento en instituciones, de las personas que se hallan en especiales condiciones de marginación. En ocasiones, además de estas actuaciones, entre las que deben primar las de carácter preventivo, es necesario disponer de Albergues o Centros de Acogida, que tengan como finalidad la asistencia directa y temporal a personas sin hogar o con graves problemas de convivencia.

El sector de Voluntariado Social presenta una red compleja que interviene en numerosos ámbitos dirigidos a personas (1. Mayores necesitadas; 2. Con discapacidad; 3. Sin hogar; 4. Inmigrantes excluidas; 5. Drogodependientes; 6. Enfermas; 7. Afectadas por el VIH/SIDA; 8. Infancia y juventud en riesgo de exclusión social; 9 . Minorías étnicas excluidas; 10 . Mujeres en riesgo de exclusión y excluidas; 11. Personas en prisión y ex reclusas; 12. Otros sectores de población que sufren exclusión social, o necesitan apoyo especial). Entendemos que todos ellos tienen gran relación con intervenciones educativas y de formación y podrían servir de campos de actuación del pedagogo. De hecho, la información ofrecida por la Junta de Andalucía (2015d) referente a los mencionados ámbitos, plantea las siguientes actuaciones, como podemos observar, todas ellas muy vinculadas a las funciones del profesional pedagogo, predominando la relativa a formación:

- Detección, atención e intervención.

- Talleres y cursos formativos.

- Formación de voluntarios y personal técnico.

- Formación, capacitación e inserción sociolaboral.

- Diseño y elaboración de campañas de sensibilización y concienciación.

- Información y asesoramiento integral.

- Fomento de la participación social, asociacionismo y voluntariado social.

- Reducción de riesgos y daños en personas afectadas por la explotación sexual.

No obstante, habremos de dejar claro en las instituciones en cuestión, que la finalidad principal de integrar a nuestros estudiantes, no es solo el voluntariado en sí mismo, sino, realizar prácticas profesionales que, además de prestar un servicio a la comunidad, sirvan para su formación, para dar a conocer nuestra profesión y como posible vía de acceder a un puesto de trabajo en dichas entidades en calidad de personal técnico.

Se entiende por Zonas de Transformación Social (Junta de Andalucia, 2015e) los espacios urbanos claramente delimitados (Barriadas) en cuya población concurren situaciones estructurales de pobreza grave y marginación social, y en los que sean significativamente apreciables problemas relacionados con: a) Vivienda, deterioro urbanístico y déficit de infraestructura, equipamiento y servicios públicos; b) Elevados índices de absentismo y fracaso escolar; c) Altas tasas de desempleo junto a graves carencias formativas profesionales; d) Significativas deficiencias higiénico sanitarias; e) Fenómenos de desintegración social. De nuevo vemos en esta modalidad, la fuerte presencia del factor educativo (para luchar contra el absentismo y el fracaso escolar) y la formación (para luchar contra las graves carencias formativas profesionales).

De los objetivos que persiguen estas zonas, destacamos la importancia concedida a la formación y actualización profesional de los técnicos que ejecutan las acciones para mejorar los niveles de profesionalización de las intervenciones. Además de las funciones vinculadas a tales actividades de formación, se alude también a las de "diagnóstico" (“...acciones que den respuesta a las necesidades 
reales..."); "diseño" y "ejecución" de modelos y programas ("Desarrollar un modelo de intervención..."); "gestión de recursos" ("...desarrollando y captando nuevos recursos, optimizando los existentes, ..."); "investigación" ("Mejorar el conocimiento ...mediante la realización de estudios y trabajos técnicos"); "comunicar, diseminar" ("Informar y sensibilizar a la opinión pública sobre la problemática de la exclusión social"); "trabajo en equipo" y "coordinación" ("Transferir, compartir e intercambiar conocimientos, experiencias y productos elaborados"); "evaluación" ("Estructurar un sistema de gestión, seguimiento y evaluación de acciones que posibilite la mejora de la calidad de los servicios prestados").

Las actuaciones desarrolladas en el área de Barriadas son:

- Implementación de proyectos (coordinar ámbitos de actuación y entidades; coordinación técnica de proyectos [SURGE, Equal-Atenea, INJUVE...]; elaborar material y herramientas de apoyo)

- Formación y Actualización profesional (cursos de formación, seminarios técnicos,...)

- Coordinación de Recursos (coordinación de programas, intervenciones, entidades,...)

- Estudios y Trabajos Técnicos (construcción de modelos de acción, análisis,...)

- Difusión y Sensibilización (organizar eventos, elaboración de material informativo,...)

- Seguimiento-Evaluación (Asesoramiento, elabora Memoria-Informes de Seguimiento,...)

\section{Drogodependencia}

En esta área (Figura 2) la "Atención Sociosanitaria" tiene por objeto prestar atención a las demandas derivadas del consumo de drogas y otras adicciones desde un modelo de atención integrada, coordinado con la red sanitaria y de servicios sociales, y adaptada a las necesidades individuales.

El modelo de intervención asistencial se estructura en torno a distintas fases del tratamiento secuenciadas y paralelas, que van desde la reducción de daños hasta la incorporación social, pasando por la desintoxicación y la deshabituación. También se contempla el seguimiento y la recaída.

La puerta de entrada al circuito terapéutico se hace a través de los "Centros de Tratamiento Ambulatorios", constituyendo el canal de acceso al resto de los recursos y programas disponibles en la red asistencial, como son las "Unidades de Desintoxicación Hospitalaria", las "Comunidades Terapéuticas", las "Viviendas de Apoyo al Tratamiento", las "Viviendas de Apoyo a la Reinserción", los "Centros de Día" y "Centros de Encuentro y Acogida". De todas ellas, entendemos que es, fundamentalmente en las tres últimas, donde más cabida tiene el desarrollo de funciones de los profesionales de la educación y, concretamente, los pedagogos.

$$
\text { Drogodependencia } \Rightarrow \begin{array}{ll}
* \begin{array}{l}
\text { Atención sociosanitaria a la drogodependencia } \\
\text { Incorporación social }
\end{array} \\
\begin{array}{l}
\text { Prevención de la drogodependencia } \\
\text { Información, formación e investigación } \\
\text { Guías, manuales, estudios y otros documentos } \\
\text { Observatorio Andaluz sobre Drogas y Adicciones }
\end{array} \\
\hline
\end{array}
$$

Figura 2. Campos de Acción del Área de Drogodependencia

La Incorporación Social tiene como objetivo conseguir la normalización e integración social plena de las personas con problemas de drogodependencias y adicciones en igualdad de condiciones al resto de ciudadanos. Contempla recursos y programas que tienen la característica de ser personalizados, estar diseñados conjuntamente con las personas usuarias y adaptados a las necesidades individuales. Entre los recursos se hallan las "Viviendas de Apoyo a la Reinserción Social" siendo idóneo para las personas que carecen de un sistema de relaciones y de vinculación con el entorno y que han logrado una estabilización en su proceso; Los "Centros de Día" potencian la formación personal y prelaboral como elemento básico 
de integración en el entorno del individuo. Entre los Programas se encuentran los siguientes: "Red de Artesanos" (concede ayudas a personas que por falta de formación tienen dificultades para acceder a un empleo, facilitándoles la formación necesaria para aprender un oficio); "Arquímedes" (a través de la contratación, dan respuesta a la socialización de los beneficiarios y ofrecen un proceso educativo que permita interiorizar valores, normas y estrategias del grupo social al que se incorpora); SEMPIN (Programa de Apoyo a la Creación de Empresas de Inserción Social); "Asesoramiento jurídico"; "Andalucía Orienta" (ofrece orientación profesional y asesoramiento especializado hacia la búsqueda de formación y empleo); "Educación Permanente de Adultos" (ofrece respuesta educativa adaptada a sus circunstancias y características); "Actuación Social en Espacios Naturales de Andalucía" (fomenta la inserción social y laboral de los colectivos en riesgo de exclusión social, al tiempo que contribuye a conservar y proteger los ecosistemas más valiosos de nuestra comunidad).

Los Programas de Prevención de la Drogodependencia insisten en prevenir, concienciar y educar en materia de drogodependencia organizándose en tres ámbitos: 1) Comunitario, 2) Familiar, 3) Educativo. En la página web de la Consejería de Igualdad y Políticas Sociales (Junta de Andalucía, 2015f) se presentan programas, materiales, estrategias, centros y documentos empleados en cada ámbito.

Se dice del Área de Información, Formación e Investigación que es transversal y complementa con sus acciones a todas las demás. Se recogen actuaciones dirigidas a profesionales, a colectivos sociales y a la población en general. Desde ella se impulsan diversas medidas para garantizar que la información, la formación y la investigación sea la más fiable, actualizada y relevante en materia de drogas y adicciones. En la citada página web, se encuentra información sobre los tres aspectos mencionados.

En el apartado relativo a información, se presentan los sistemas empleados, concretamente, el "Sistema de información del Observatorio Andaluz sobre Drogas y Adicciones", el "Teléfono de Información sobre Drogodependencias y Adicciones", las "Campañas institucionales" y los "Estudios de prevalencia del consumo de drogas: actitudes, motivaciones, consecuencias, factores de riesgo, factores de protección".

La formación sobre dependencias y adicciones, se plantea dirigida a profesionales relacionados con las drogodependencias y adicciones (Curso Básico en Información/Formación sobre Drogodependencias y Adicciones) y estudiantes (Asignaturas de tercer ciclo o libre configuración en colaboración con las universidades andaluzas).

En cuanto a investigación, se financian proyectos de investigación estableciendo convenios de colaboración con distintas universidades y con otras instituciones investigadoras andaluzas; se ha creado un foro integrado por técnicos especialistas en drogodependencias y agentes de la comunidad; y un servicio de asesoramiento y apoyo a la investigación científica.

El área relativa a "Guías, manuales, estudios y otros documentos" presenta toda una serie de Estudios, Programas, Memorias, Manuales, Guías, Mapas, Informes e Investigaciones sobre el tema en cuestión.

Por último, el Observatorio Andaluz sobre Drogas y Adicciones tiene entre otras funciones: Coordinar un sistema de Información; Realizar análisis periódicos; Realizar propuestas apoyadas en estudios y evaluaciones para la toma de decisiones; Asesorar en las acciones a adoptar; Desarrollar estudios e investigaciones; Promover encuentros técnicos entre profesionales, expertos y movimientos sociales implicados; Colaborar en el intercambio de información entre las distintas Administraciones; Elaborar informes; Participar en la producción, coordinación y divulgación de documentación; etc.

\section{Personas Mayores}

Esta área se centra en actuaciones dirigidas al desarrollo, coordinación y promoción de políticas para el bienestar de las personas mayores desarrollando funciones relativas a:

- Ordenación, gestión y coordinación de Centros y Servicios de atención y protección a personas mayores, tanto públicos como concertados.

- Gestión y control de las ayudas económicas.

- Diseño, realización y evaluación de los servicios y programas específicos, especialmente los relativos a la atención a la dependencia y al fomento del envejecimiento activo.

- Autorización y acreditación de centros de atención a personas mayores. 


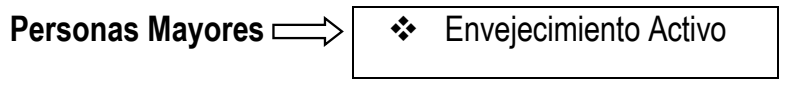

Figura 3. Campos de Acción del Área de Personas Mayores

Las actuaciones (Junta de Andalucía, 2015g) previstas para personas mayores están referidas a Normativa de centros residenciales de mayores, Modelos de solicitud y Envejecimiento Activo, interesando muy especialmente ésta última a los fines del estudio ya que, en ella, existen dos modalidades en las que el pedagogo puede desempeñar plenamente sus funciones centradas, fundamentalmente, en la formación:

Las Aulas Universitarias de Personas Mayores como espacios de formación, participación, y convivencia, proporcionan la oportunidad de incorporarse a programas de formación científica, tecnológica, cultural,... El programa ofrece módulos y cursos formativos, jornadas, talleres, conferencias y visitas culturales programadas en las universidades andaluzas. El profesorado que imparte la docencia pertenece a las universidades andaluzas, aunque colaboran también profesionales expertos de distintas universidades e instituciones públicas y privadas. Estas actuaciones se desarrollan en las universidades de la Comunidad Autónoma de Andalucía, financiadas por la Consejería de Igualdad y Bienestar Social y apoyadas por otras Administraciones Públicas.

Los Centros de Participación Activa son centros de promoción del bienestar de las personas mayores tendentes al fomento de la convivencia, la integración, la participación, la solidaridad y la relación con el medio social. Además de las actividades sociales, de autoayuda, culturales, recreativas, deportivas, musicales, artesanales, turísticas, etc., algunos Centros de Participación Activa ofrecen también servicios de comedor, de orientación jurídica, aulas de informática,...

\section{Infancia y Familias}

La Dirección General de Infancia y Familias (Figura 4) desarrolla las competencias de la Comunidad Autónoma en materia de protección de menores y promoción de las familias y la infancia (Junta de Andalucía, 2015, h). De las varias áreas de actividad destacamos las que entendemos pueden representar campos de acción de los profesionales de la educación.

Infancia y Familias $\Rightarrow \begin{array}{ll}\text { Atención a infancia y adolescencia } \\ \text { Apoyo a la familia } \\ \text { Registro de mediación familiar } \\ \text { Separación de la familia biológica y atención al menor } \\ \text { Acogimiento familiar y Adopción } \\ \text { Programa }+18 \\ \text { Atención a menores inmigrantes }\end{array}$

Figura 4. Campos de Acción del Área de Infancia y Familia

El ejercicio de la acción protectora que implica la "Atención a la Infancia y a la Adolescencia" requiere recursos sociales que se clasifican según los siguientes niveles de intervención:

- Atienden al menor en su medio natural, evitándole la separación de su familia y entorno, actuando en el medio en que vive, directamente donde se producen los problemas. 
- Implican separación de la familia biológica y empleo de medidas alternativas de carácter familiar, procurando la salida del niño de su medio (temporal o definitiva), ofreciendo un medio familiar alternativo que garantice su desarrollo en condiciones normalizadas.

- Implican separación de su familia e internamiento en centros, para proteger al niño de un daño o riesgo mayor, mientras se resuelve la situación que los provoca, tratando que su aplicación sea siempre temporal y procurando la reinserción del niño a su medio natural.

Desde el área de Prevención y Apoyo a las Familias se efectúan actuaciones dirigidas a:

- Promover planes integrales dirigidos a la protección de la infancia y prevención de situaciones de riesgo.

- Fortalecer las medidas de apoyo técnico y económico dirigidas a las familias con menores a su cargo, con carácter preventivo y temporal.

- Implantar programas específicos dirigidos a los grupos más vulnerables de familias y menores que viven, coyunturalmente, una situación de crisis.

- Instaurar programas y recursos que, desde la perspectiva de la intervención y tratamiento, van destinados a situaciones identificadas como de alto riesgo.

Las acciones desarrolladas se concretan en: 1) Plan Integral de Atención a la Infancia (actuaciones a desarrollar por las administraciones públicas para garantizar los derechos de los menores). De él, destacamos el objetivo general relacionado con nuestro campo profesional: "Lograr el acceso de todos los niños y niñas a los sistemas educativos, culturales y recreativos, estableciendo niveles de mayor calidad, medidas compensatorias para paliar las desigualdades, respondiendo a la diversidad e instaurando cauces de participación y corresponsabilidad"; 2) Medidas generalistas (centradas en ayudas económicas a familias numerosas, partos múltiples, etc.); 3) Programas dirigidos a la detección y prevención del maltrato infantil (diferentes medios, teléfono y otros para notificar posible maltrato); 4) Programas dirigidos a familias e infancia en situación de vulnerabilidad (Programa de ayudas económicas familiares; Programas "Espacio facilitador de relaciones familiares"); 5) Programas de Tratamiento (Programa de tratamiento a familias con menores; Programas de atención a menores víctimas de abusos sexuales)

Un aspecto común a todas las actuaciones relativas a "Programas" viene representado por la existencia de un equipo interdisciplinar que las desarrolla. En la información revisada (Junta de Andalucía, 2015i) aparecen como profesionales constituyentes de tales equipos, psicólogos, educadores, trabajadores sociales, en ocasiones, juristas. Ante ello cabe plantearse la pregunta ¿no podrían realizar un buen papel los pedagogos especialistas en materia de educación y formación, máxime, si advertimos que muchas de las acciones están relacionadas con el sector educativo? Buen ejemplo de ello lo constituyen las actuaciones asignadas a los equipos en los Programas relativos a "Espacio facilitador de relaciones familiares" para los que se dice,

\footnotetext{
“...irán encaminadas a realizar las intervenciones técnicas y de orientación necesarias, dirigidas entre otras, a la adopción de pautas educativas, reducción de conflictos, etc., ofreciendo directrices a los padres, las madres y otros miembros de la familia sobre la atención que han de prestar a los hijos e hijas, a fin de mejorar las relaciones paterno/materno-filiales y las habilidades parentales".
}

Será interesante indagar y comprobar si realmente los pedagogos están excluidos de estos programas en la realidad laboral que representa el mundo real, cuáles serían los motivos, cómo y por qué se justifica su ausencia, etc.

La finalidad del proceso de Mediación Familiar (Comunidad Autónoma de Andalucia, 2009a, 2009b) es, con carácter general, lograr que las partes en conflicto alcancen acuerdos equitativos, justos, estables y duraderos, contribuyendo a evitar, en su caso, la apertura de procedimientos judiciales o contribuir a la resolución de los ya iniciados. 
Aquí, sí aparece ya la figura del pedagogo como profesional de pleno derecho ya que se indica expresamente que la mediación familiar se ha de efectuar por profesionales de titulación universitaria 0 título de grado en las disciplinas de Derecho, Psicología, Psicopedagogía, Sociología, Pedagogía, Trabajo Social o Educación Social, o cualquier otra homóloga de carácter educativo, social, psicológico o jurídico. Para ello, la persona mediadora debe estar inscrita en el "Registro de Mediación Familiar" de Andalucía, y deberá acreditar:

\begin{abstract}
Formación específica: “... superar un curso con duración no inferior a 300 horas o su equivalente en el Sistema Europeo de Transferencia de Créditos (ECTS) de las que, al menos 60 , tendrán carácter práctico con un mínimo del $80 \%$ de asistencia y con el contenido que se establezca por orden de la Consejería competente en materia de familias". La acreditación de dicha formación específica de postgrado, impartida por Universidades... (Junta de Andalucía, 2012, art. 5.2. )

"Formación continua" que "...tendrá un carácter trienal y consistirá en la realización de nuevos cursos de formación de, al menos 60 horas acumulables en materias relacionadas con la mediación familiar. (Junta de Andalucía, 2012, art. 5.3)
\end{abstract}

En relación al área de actividad Separación de la familia biológica y atención al menor, se indica que la familia es el medio idóneo para la formación integral y el desarrollo armónico del niño. No obstante, existen determinados factores que pueden incidir en este medio, transformándolo en hostil para el niño e impidiendo su normal desarrollo. En estos casos, se hace necesaria la intervención de la Administración, promoviendo los recursos necesarios, mediante intervenciones de apoyo a la familia, con objeto de que ésta supere la situación, sin necesidad de separar al niño de su medio. No obstante, cuando la gravedad del caso detectado es extrema, se hace necesario adoptar otro tipo de medidas que implican la separación del menor de su familia biológica, con objeto de garantizarle la protección adecuada. Tales medidas se inician a través del denominado "expediente de protección" recibiendo información sobre el posible desamparo de los menores, elaborando y recabando informes necesarios para su estudio y resolviendo, en su caso, declarar situación de desamparo, asumir su tutela y adoptar medidas adecuadas para el ejercicio de la guarda del menor a través de los siguientes recursos:

- Programa de Acogimiento Familiar. El acogimiento familiar -que puede ser simple o permanentees la convivencia e integración en una familia acogedora de un niño que debe ser separado temporalmente de su familia, evitando su estancia en una institución. Tal medida da al menor posibilidad de desarrollarse en una familia (en la propia extensa o en otra), a la vez que mantener la vinculación con su núcleo familiar más cercano.

- Programa de Acogimiento Preadoptivo y Adopción. La adopción se basa en dos principios fundamentales: estar configurada como elemento de plena integración familiar y la prevalencia del interés del adoptado sobre todos los demás. La adopción está pensada para proporcionar una familia a niños que carecen de ella, o que teniéndola, no pueden permanecer en ella por distintos motivos, garantizándoles, a través de esta nueva relación familiar, la atención necesaria para su desarrollo.

- Acogimiento residencial en Centros de Protección de Menores. Los centros de protección, constituyen espacios donde se atiende a menores, promoviendo el desarrollo integral como personas, combinando la calidad técnica y la calidez humana. Es por tanto, un entorno de convivencia y formativo en el que se garantiza, de un lado, recursos profesionales y materiales suficientes y adecuados; de otro, calidez que posibilite relaciones afectivas inspiradas en los estilos y características de una familia normalizada. El acogimiento en centro residencial:

- Conlleva, en la mayoría de los casos, una intervención paralela en el medio socio-familiar del menor, trabajando con su familia de origen, al objeto de prestar apoyo necesario para que supere la situación que motivó la aplicación de la medida y puedan retornar a su medio familiar. 
- Constituye una alternativa válida a utilizar cuando resulte más beneficiosa para el menor de edad por sus condiciones personales. El perfil de los menores atendidos suele estar representado por adolescentes y jóvenes de ambos sexos, menores procedentes de la inmigración y menores con una problemática que requiere una atención especial.

Los centros de protección se clasifican, en "Casas" (núcleos de convivencia ubicados en viviendas normalizadas que siguen patrones comunes a los hogares familiares) y "Residencias" (agrupan varios núcleos de convivencia donde las personas acogidas comparten habitualmente espacios comunes).

El Proyecto Educativo Marco para los Centros de Protección de Menores en el ámbito de la Comunidad Autónoma de Andalucía (2005a, b) articula los Programas Residenciales (instrumentos técnicos para orientar la acción de los centros, de acuerdo al perfil de los menores) en los siguientes tipos:

1. De Acogida Inmediata. Destinados a la primera acogida, diagnóstico y derivación de las personas menores de edad hacia las distintas alternativas.

2. Dedicados a la Atención Residencial Básica: Se trata del acogimiento residencial de carácter general y normalizado que incluye la atención a la diversidad desde una perspectiva integradora. Son los que mejor y de forma más general reflejan la vocación socializadora de acogimiento residencial y los que se desarrollan en la mayor parte de los Centros de Protección de Menores.

3. Específicos de Atención a la Diversidad: Atienden a menores cuyas necesidades específicas exigen atención diferenciada. Se desarrollan en centros que reúnen condiciones adecuadas para un acogimiento terapéutico. Los perfiles que se incluyen en estos programas son: graves trastornos del comportamiento; relacionados con patologías psicosociales y educativas; graves trastornos de conducta; asociados con patologías psiquiátricas y grave discapacidad

4. Complementarios o de apoyo al acogimiento residencial. Entidades colaboradoras que desarrollan programas y recursos complementarios y de apoyo al acogimiento residencial en Centros de Protección de Menores.

El Programa + 18 (Pp+18). Atención ante la Mayoría de Edad para jóvenes que son o han sido tutelados, parte de las necesidades individuales detectadas en este grupo, que, al cumplir los 18 años, es considerado por la legislación vigente como sujetos que han alcanzado la madurez y, por tanto, poseen plena capacidad para vivir de forma autónoma. Trata de permitirles enfrentarse a su nueva situación de autonomía e independencia con unas mínimas garantías para su plena integración sociolaboral. Promueve la integración de jóvenes desde una perspectiva integral, apoyándose en cuatro pilares fundamentales:

- La madurez y desarrollo personal y social

- La orientación vocacional y formación para el empleo

- Logro de recursos básicos, especialmente, vivienda.

- Acceso al empleo, promoviendo la Formación Ocupacional e Inserción laboral para jóvenes que han sido tutelados por la Junta de Andalucía.

A través del Programa, desde los centros de protección, se les orienta para la vida autónoma. Las acciones se inician antes de alcanzar la mayoría de edad y se puede extender, en algunos casos, hasta los 25 años, asegurándoles recursos y profesionales que les orienten y acompañen para lograr sus primeras experiencias laborales, e incluso el acceso a la vivienda. Para este programa hay dos modalidades de recursos:

- De Alta Intensidad: Pisos de autonomía, donde se proporciona una atención integral que se traduce en la cobertura de todas las necesidades para jóvenes que han tenido que abandonar los centros de menores y carecen de cualquier posibilidad para vivir de forma autónoma al cumplir los 18 años.

- De Media Intensidad: compuestos por una red de centros de día, donde se realizan todas las actuaciones programadas, con un seguimiento constante y con las garantías de formación suficientes para lograr su integración social y laboral. Este apoyo se lleva a cabo mediante 
que, una vez más, están ausentes los pedagogos. Este hecho llama la atención, sobre todo, porque uno de los aspectos a considerar son los factores culturales, en los que se analiza la vinculación de la persona con el sistema educativo en términos de nivel de estudios realizados, rendimiento escolar y fracaso escolar. Siendo tales temas, netamente educativos, nos preguntamos ¿por qué no se tienen en cuenta a especialistas en ese campo?

Dentro de la gran amplitud que supone el sector de Servicios y Prestaciones para Personas con Discapacidad, tratamos los aspectos más estrechamente vinculados a las actuaciones que los profesionales de la educación (pedagogos) podrían realizar deteniéndonos, de una parte, en el gran campo de los Servicios Sociales Especializados (los generales fueron tratados en el apartado "Servicios Sociales e Inclusión", Figura 1); de otra, por razones obvias, en las medidas articuladas en el campo de la Educación.

De los Servicios Especializados presentamos brevemente la variedad existente dentro de los "Centros Residenciales", "Centros de Día" y "Programas de Respiro Familiar":

$\checkmark$ Los Centros Residenciales se configuran como recursos de atención integral destinados a las personas que, no pudiendo ser asistidas en su medio familiar, lo precisan temporal o permanentemente. Los hay de varios tipos:

- Residencia para Personas Gravemente Afectadas. Destinada a atender, en régimen de internado, a personas con una discapacidad tan grave que precisen de ayuda para realizar las actividades de la vida diaria y no puedan ser asistidos en su medio familiar.

- Residencia de Adultos. Destinada al acogimiento y convivencia, temporal o permanente, en régimen de internado, de personas con discapacidad que disfrutan de cierta autonomía personal, y que, por razones familiares tengan dificultad para la vida familiar normalizada y la integración social.

- Viviendas Tuteladas. Destinadas a personas con discapacidad con un grado suficiente de autonomía personal. Consisten en pequeñas unidades de alojamiento y convivencia ubicadas en edificios o zonas de viviendas normalizadas y están dotadas del equipamiento y servicios necesarios para el alojamiento, manutención y apoyo social de quienes las habiten.

- Centros de Recuperación de Minusválidos Físicos (CRMF). Ofrecen en régimen residencial y de día, servicios de rehabilitación médico-funcional y psico-social, formación cultural y profesional ocupacional y ocio a personas con minusvalía física que precisan todos 0 algunos de estos servicios para su recuperación y/o integración social.

- Casas Hogar. Centros residenciales de alojamiento y convivencia para personas a partir de 18 años con escaso nivel de autonomía personal consecutiva a una enfermedad mental, debiendo garantizar la cobertura de las necesidades de atención no sanitaria de los pacientes. Tienen una función sustitutoria del hogar familiar, ya sea de forma temporal o permanente.

- Viviendas Supervisadas. Unidades de alojamiento y convivencia ubicadas en edificios o zonas de viviendas normalizadas, destinadas a personas con enfermedad mental que posean un grado suficiente de autonomía personal, por lo que no precisan necesariamente personal específico durante las 24 horas. Cuentan con la distribución de espacios de una vivienda familiar, dotadas del equipamiento y servicios necesarios para el alojamiento, manutención y apoyo social de quienes las habitan.

$\checkmark$ Los Centros de Día: Establecimientos destinados a la atención de las personas que no puedan integrarse -transitoria o permanentemente- en un medio laboral normalizado, o que por su gravedad, necesiten atención continuada y no puedan ser atendidas por su núcleo familiar durante el día. Se clasifican en:

- Unidades de Estancia Diurna. Destinadas a la atención, en régimen de media pensión, de personas con discapacidad tan grave que dependan de otra para las actividades de la vida cotidiana y no puedan ser atendidas por su unidad familiar durante el día.

- Unidades de Estancia Diurna con Terapia Ocupacional. Centros destinados a la atención de personas con discapacidad en edad laboral que no puedan integrarse, transitoria o permanentemente, en un medio laboral normalizado. Pretenden su integración social y, en su caso, laboral, mejorar su adaptación personal y social, normalizar sus condiciones de vida y, cuando sea posible, habilitarles laboralmente, garantizando la igualdad de oportunidades entre mujeres y hombres con discapacidad. 
- Talleres Polivalentes y Ocupacionales Prelaborales. Centros destinados a personas con enfermedad mental crónica, que no puedan acceder a un recurso laboral o de formación profesional normalizado, y que son derivadas y atendidas por dispositivos de salud mental.

- Centros Sociales. Centros de promoción del bienestar de personas con enfermedad mental, tendentes a fomentar la convivencia, la participación, la solidaridad y el uso del tiempo libre, propiciando la integración dentro de la comunidad y un funcionamiento lo más autónomo posible. Su actividad estará orientada a adquirir hábitos de vida normalizados: horarios, distribución del tiempo libre, deportes, manualidades, actividades culturales y educativas. Contarán con las dependencias necesarias para poder ofrecer los servicios a los usuarios.

$\checkmark$ El Programa de Respiro Familiar. Destinado a colaborar con las familias cuidadoras de personas con discapacidad dependientes, a las que se presta apoyo mediante un servicio residencial de duración variable, en periodos que oscilan entre 24 horas y un mes, con carácter prorrogable, por motivo de descanso, enfermedad u hospitalización de la persona cuidadora, emergencias y otras circunstancias análogas. En función del grado de dependencia de la persona, existen dos modalidades de respiro familiar: a) Para personas con discapacidad gravemente afectadas; b) Para personas con discapacidad con menor nivel de dependencia.

Estudiando la respuesta que el Sector Educación ofrece ante la Discapacidad, advertimos que el alumnado con necesidades educativas especiales derivadas de discapacidad y/o trastornos graves de conducta, es atendido por (Tabla 2) profesorado ordinario, especialista, y de apoyo especializado. Existen también otros profesionales que desarrollan su labor dentro de equipos, (Departamentos de Orientación en los centros; Equipos de Orientación Educativa de Zona y Equipos de Orientación Educativa Especializados en diferentes discapacidades) y aquellos que actuando como monitores, intérpretes de lengua de signos o educadores, atienden las necesidades educativas especiales de los sujetos con discapacidad.

Tabla 2. Profesionales de la Educación ante necesidades educativas especiales

\begin{tabular}{|l|l|}
\hline \multirow{3}{*}{ Profesorado especializado } & Profesorado de apoyo curricular \\
\cline { 2 - 2 } & Maestros especialistas en Pedagogía Terapeútica \\
\cline { 2 - 2 } & Maestros especialistas en Audición y Lenguaje \\
\hline \multirow{3}{*}{ Otros profesionales (Equipos) } & Departamento de Orientación \\
\cline { 2 - 2 } & Equipo de Orientación Educativa de zona \\
\cline { 2 - 2 } & Equipo de Orientación Educativa Especializado \\
\hline \multirow{3}{*}{ Otros profesionales } & Monitores de Educación Especial \\
\cline { 2 - 2 } & Intérpretes de Lengua de signos española \\
\cline { 2 - 2 } & Educadores Sociales \\
\hline
\end{tabular}

El profesorado de apoyo curricular a alumnos con necesidades educativas especiales, son profesores de educación secundaria que apoyan y complementan la labor del profesorado ordinario. Los maestros especialistas en Pedagogía Terapéutica (PT), atienden e imparten docencia directa para el desarrollo del currículo coordinándose con los profesionales de la orientación educativa. Los especialistas en Audición y Lenguaje $(A L)$ se centran en alumnado con retraso, trastornos y patologías del lenguaje oral y escrito, y con los que tienen discapacidad auditiva.

Los Departamentos de Orientación (en los Institutos de Educación Secundaria) organizan, promueven y coordinan las actividades de orientación educativa en el centro. Entre las funciones relativas a la atención al alumnado con necesidades educativas especiales, destacan (Junta de Andalucía, 2010):

- Realizar la evaluación psicopedagógica del alumnado según lo previsto en la normativa.

- Asesorar a los departamentos de coordinación didáctica y al profesorado, y colaborar en el desarrollo de medidas y programas de atención a la diversidad y en la prevención y detección temprana de problemas de aprendizaje.

- Colaborar con el equipo directivo en la elaboración del Plan de Orientación y Acción Tutorial.

- Asesorar al alumnado sobre opciones que ofrece el sistema educativo y la transición al mundo laboral. 
- Asesorar al equipo directivo y al profesorado la aplicación de diferentes medidas de atención a la diversidad, especialmente las orientadas al alumnado con necesidades específicas de apoyo educativo.

Los Equipos de Orientación Educativa pueden estar integrados por profesionales de psicología, pedagogía, medicina, trabajo social, especialistas en educación compensatoria o audición y lenguaje. Las funciones dirigidas al alumnado con necesidades educativas especiales, son:

- Asesorar a los centros en la elaboración, aplicación y evaluación del Plan de Centro y el Proyecto Educativo, en aspectos ligados a orientación educativa y atención a la diversidad.

- Atender las demandas de evaluación psicopedagógica del alumnado que la requiera y proponer la modalidad de escolarización más adecuada recogida en el "dictamen de escolarización".

- Asesorar al profesorado en el tratamiento educativo de la diversidad de aptitudes, intereses y motivaciones del alumnado, y colaborar en la aplicación de medidas educativas.

- Participar en el diseño y desarrollo de programas de refuerzo, adaptación y diversificación curricular de los centros de la zona.

- Asesorar a las familias, participando en el diseño y desarrollo de programas formativos de padres.

Los Equipos de Orientación Educativa Especializados (uno por provincia). Su objetivo prioritario es atender las necesidades educativas especiales en colaboración y coordinación con los Equipos de Orientación Educativa de zona, con los Equipos de Orientación de cada centro de Educación Infantil y Primaria y con los Departamentos de Orientación. Su misión consiste en:

- Asesorar al profesorado sobre atención al alumnado con discapacidad y a sus familias.

- Colaborar con el Departamento de Orientación y Equipo de Orientación Educativa a identificar y valorar las necesidades educativas especiales del alumnado y a elaborar el "dictamen de escolarización".

- Contribuir a la formación especializada del profesorado y profesionales de los Equipos de Orientación Educativa y Departamento de Orientación, proporcionando información sobre características, necesidades, procedimientos de intervención con dicho alumnado.

- Colaborar en la elaboración de la adaptación curricular, especialmente en los aspectos relacionados con el tratamiento especializado de la discapacidad.

- Adaptación del puesto de trabajo del alumnado y provisión de medios técnicos necesarios para hacerlo.

- Enseñar y entrenar a este alumnado a manejar las ayudas técnicas y facilitarles material didáctico y de apoyo complementario que le posibilite el desarrollo y el seguimiento del currículo.

Están concebidos para la atención educativa a alumnos con necesidades educativas especiales asociadas a discapacidad motriz, auditiva y visual; trastornos graves de conducta; trastornos del espectro autista; y a menores de 6 años que presenten trastornos en el desarrollo o riesgo de padecerlo. Los Equipos de Orientación Educativa Especializados en discapacidad motriz, auditiva y visual, lo constituyen profesionales expertos en atención educativa y en ayudas técnicas necesarias para estos tipos de discapacidades. Su finalidad es adaptar el estudio mediante el empleo de nuevas tecnologías aplicadas a la educación, la utilización de ayudas técnicas y sistemas de comunicación alternativa o aumentativa, así como asesoramiento a padres y profesorado en el empleo de estos recursos.

Los Equipos de Orientación Educativa especializados en trastornos graves de conducta (TGC), del espectro autista (TEA) y en atención temprana (AT) se centran en el asesoramiento para la atención educativa del alumnado que los padecen y también de los de educación infantil que presentan riesgo de padecerlos.

Se dice que tales equipos, están compuestos por profesionales de la psicología, pedagogía, trabajo social, profesorado de apoyo, personal técnico de rehabilitación básica, rehabilitación visual, instrucción tiflotécnica y de Braille. 
Por último, presentamos las características de otros profesionales que atienden al alumnado con necesidades educativas especiales:

Monitores de educación especial: Se centran en la atención al alumnado con discapacidad, en coordinación con el profesorado especializado, especialmente en las actividades de alimentación, aseo personal, movilidad dentro y fuera del aula, uso de ayudas técnicas, aplicación de programas de modificación de conducta, etc.

Intérpretes de lengua de signos española. Son profesionales que intervienen en los Institutos de Educación Secundaria. Su principal función consiste en servir de puente comunicativo, interpretando la lengua de signos española, entre el alumnado y el profesorado, así como con entre el resto de los compañeros oyentes, facilitando el acceso a las enseñanzas y la comprensión de las explicaciones e instrucciones del contexto escolar. Para desarrollar sus funciones deben estar en posesión de la titulación de Técnico Superior en Interpretación de Lengua de Signos.

Educadores sociales. Intervienen en la aplicación de medidas para la mejora de la convivencia y la colaboración con el profesorado, en el seguimiento del alumnado absentista, mediación en conflictos alumnado-centro-familia y desarrollo de programas para la educación de valores y la integración multicultural, entre otras actuaciones. Son profesionales adscritos a los Equipos de Orientación Educativa, actuando tanto en los Centros de Educación Infantil y Primaria como en los Institutos de Educación Secundaria.

Por último pasamos a presentar "Otras medidas para la atención al alumnado con necesidades educativas especiales":

- Aulas hospitalarias y unidades de salud mental infantil y juvenil. Para compensar los efectos originados en el proceso educativo por el internamiento hospitalario prolongado de escolares, las Consejerías de Educación y de Igualdad y Políticas Sociales, vienen desarrollando desde 1988, un programa de actuación en virtud del cual los hospitales de Andalucía (ciudades y principales comarcas), disponen de aulas hospitalarias con docentes dependientes de la Consejería competente, para prevenir y evitar el retraso o desfase curricular en el alumnado durante el periodo de hospitalización. De igual modo, la mayoría de las Unidades de Salud Mental Infantil y Juvenil cuentan con profesorado con ese objetivo.

- Programas de atención educativa domiciliaria. La Consejería de Educación dispone de profesorado para la atención del alumnado que por motivos de enfermedad permanece en su domicilio durante períodos de tiempo de media a larga duración, para favorecer su posible y posterior continuidad educativa y evitar el retraso en el logro de conocimientos, destrezas y habilidades sociales y escolares, con el referente del currículo del grupo educativo en el que estaba integrado. Intervienen profesores itinerantes en coordinación con los tutores de los centros educativos en los que están escolarizados. En algunos casos, estos profesores son docentes de los propios centros o mentores titulados asignados por la dirección de los mismos.

\section{Atención a la Dependencia}

En este a área destacamos (Figura 6) las actividades de mayor relevancia para nuestro estudio.

\begin{tabular}{|c|c|}
\hline Atención a la Dependencia $\Longrightarrow$ & $\begin{array}{l}\text { * Catálogo de prestaciones } \\
* \text { Recursos didácticos } \\
\text { * Plan de formación }\end{array}$ \\
\hline
\end{tabular}

Figura 6. Campos de Acción del Área de Atención a la Dependencia

Revisado el Catálogo de Prestaciones advertimos que éstas, presentan gran similitud con los servicios para personas mayores y para personas con discapacidad, ya descritos en apartados anteriores (Servicio 
de Prevención de las situaciones de dependencia; de promoción de la autonomía personal; de Centro de Día y Noche; de Atención Residencial,...)

Respecto a los Centros de Día se especifica que deben contar con una programación detallada e individualizada indicando objetivos, metodología y evaluación. Tal exigencia es prueba evidente de la labor que puede desempeñar el pedagogo ya que una de sus funciones como profesional es el diseño y desarrollo de programas formativos.

Existen varias modalidades de servicio en función de las distintas situaciones de discapacidad: a) intelectual; b) física y/o visual o parálisis cerebral; c) intelectual y graves trastornos de conducta; d) trastornos del espectro autista; e) terapia ocupacional; f) enfermedad mental. Los que cuentan con terapia ocupacional, a través de la realización de tareas prelaborales u ocupacionales pretenden la integración social y, en su caso, laboral de las personas destinatarias, mejorar su adaptación personal y social, normalizar sus condiciones de vida y, cuando sea posible, habilitarles laboralmente garantizando la igualdad de oportunidades entre hombres y mujeres.

Respecto a los Recursos Didácticos, decir que existe numeroso material ya elaborado, entendiendo que éste es un campo en el que los profesionales pedagogos tienen mucho que aportar respecto a su mejora y actualización y en la elaboración de nuevos materiales, así como, asesorando en cuanto a sus características y exigencias didácticas.

Situándonos en la actividad Plan de Formación, observamos la existencia de cinco tipos de planes formativos dirigidos a profesionales que prestan sus servicios en el complejo ámbito de la acción social: Así, hallamos los dirigidos a profesionales de 1). la Consejería de Igualdad y Bienestar Social (CIBS) y de sus Delegaciones Provinciales (DDPP); 2) los Centros de Valoración y Orientación; 3) los Servicios Sociales Comunitarios; 4) la Red de Centros y Servicios del Sistema para la Autonomía y Atención a la Dependencia (SAAD); 5) todos los centros directivos y entidades implicadas en el proceso de reconocimiento de la situación de dependencia y acceso a los servicios y prestaciones del SAAD.

Con objeto de ganar en claridad, se ha creído conveniente clasificarlos y presentarlos agrupados (tabla 3) entendiendo que, de este modo, podremos apreciar los elementos comunes y las posibles diferencias, evitando por tanto, repeticiones innecesarias.

Tabla 3. Planes Formativos del Personal del Área de Atención a la Dependencia

\begin{tabular}{|l|c|c|c|c|}
\hline \multicolumn{1}{|c|}{ OBJETIVOS } & C. & V. & SSCC & $\begin{array}{c}\text { C y S. } \\
\text { SAAD }\end{array}$ \\
\hline O.Generales: & & & \\
\hline $\begin{array}{l}\text { Dotar a los profesionales de los conocimientos, habilidades y actitudes } \\
\text { necesarias que permitan desarrollar su trabajo de forma ágil y eficaz }\end{array}$ & $X$ & $X$ & $X$ & $X$ \\
\hline $\begin{array}{l}\text { Fortalecer capacidades y conocimiento en materia de género y su } \\
\text { relación al proceso presupuestario de centros directivos y entidades } \\
\text { implicadas en el reconocimiento de situaciones de dependencia y acceso } \\
\text { a servicios y prestaciones del SAAD. }\end{array}$ & $X$ & $X$ & $X$ & $X$ \\
\hline O.Específicos: & & & & \\
\hline Integrar el principio de igualdad de género en la planificación y presupuesto & $X$ & & & \\
\hline Integrar igualdad de género en la valoración de la situación de dependencia & & $X$ & & \\
\hline $\begin{array}{l}\text { Integrar la dimensión de género al elaborar Programa Individual de } \\
\text { Atención }\end{array}$ & & $X$ & $X$ \\
\hline Actualizar los conocimientos en relación a desarrollo normativo posterior & $X$ & $X$ & $X$ & \\
\hline Motivar la reflexión de los profesionales sobre el desarrollo de normativa & $X$ & & & \\
\hline $\begin{array}{l}\text { Hacer balance del Sistema para la Autonomía Personal y Atención a la } \\
\text { Dependencia }\end{array}$ & $X$ & $X$ & $X$ & \\
\hline Profundizar en el manejo de las herramientas informáticas de gestión & $X$ & $X$ & $X$ & \\
\hline $\begin{array}{l}\text { Analizar las necesidades formativas de los profesionales, proponiendo un } \\
\text { plan de formación continua }\end{array}$ & $X$ & $X$ & $X$ \\
\hline
\end{tabular}




\begin{tabular}{|l|c|c|c|}
\hline $\begin{array}{l}\text { Entrenar al personal, en competencias propias de su puesto de trabajo. } \\
\text { (habilidades de comunicación, destrezas psicosociales, de aplicación, .. }\end{array}$ & $X$ & $X$ & \\
\hline $\begin{array}{l}\text { Analizar aspectos relativos al protocolo de actuación para el } \\
\text { reconocimiento de la situación de dependencia }\end{array}$ & $X$ & & \\
\hline $\begin{array}{l}\text { Analizar las estrategias y criterios a seguir en función de las distintas } \\
\text { tipologías de situaciones que provocan dependencia }\end{array}$ & $X$ & & \\
\hline $\begin{array}{l}\text { Comprender las implicaciones del Sistema para la Autonomía Personal y } \\
\text { Atención a la Dependencia en Andalucía. }\end{array}$ & & $X$ & $X$ \\
\hline $\begin{array}{l}\text { Ejecutar con destreza los procedimientos y/o protocolos establecidos para } \\
\text { la atención a usuarios }\end{array}$ & & $X$ & $X$ \\
\hline $\begin{array}{l}\text { Conocer en profundidad las prestaciones y servicios del Sistema para la } \\
\text { Autonomía Personal y Atención a la Dependencia, estudiando su idoneidad } \\
\text { en función de cada caso particular }\end{array}$ & & $X$ & \\
\hline $\begin{array}{l}\text { Conocer, identificar y seleccionar los recursos más adecuados para cada } \\
\text { usuario }\end{array}$ & & $X$ & \\
\hline $\begin{array}{l}\text { Planificar, desarrollar y evaluar el plan individual de atención adecuado a } \\
\text { cada usuario, promoviendo, en lo posible, la promoción de autonomía } \\
\text { personal y la prevención de mayor dependencia. }\end{array}$ & & & \\
\hline
\end{tabular}

La tabla está compuesta por cinco columnas, la primera de la izquierda muestra los objetivos generales y específicos tal como se denominan en el material analizado. Las restantes representan los cuatro planes formativos dirigidos a los profesionales de la Consejería (C.), a los profesionales valoradores de los Centros de Valoración y Orientación (V), a los de Servicios Sociales Comunitarios (SSCC) y a los de Centros y Servicios del Sistema para la Autonomía y Atención a la Dependencia (C y S. SAAD).

Señalamos con $X$ la presencia del objetivo en cuestión, en los distintos planes de formación, así, observamos que todos ellos concuerdan en el mismo objetivo general relativo a los conocimientos de todo tipo que deberán poseer los profesionales para desarrollar su trabajo. A los objetivos específicos resultantes y su presencia en los varios planes de formación se ha llegado tras un proceso de análisis, comparación, valoración y síntesis. Se han eliminado algunos por ser idénticos al general (en tercer y cuarto programa); se han resumido ideas, se ha simplificado la redacción, se han respetado y extraído las ideas esenciales; se han eliminado los repetidos en los varios programas (indicando con X su presencia en varios de ellos); se han integrado en uno global los de carácter parcial referidos a un mismo tema; se han construido algunos integrando elementos parciales de varios, etc.

El quinto plan de formación ("Para la Integración de la Perspectiva de Género en el Programa Presupuestario 31R"), está dirigido a todos los profesionales de los centros directivos y entidades ya indicados (columnas 2 a 5). Aparece representado por el segundo objetivo general y los tres primeros objetivos específicos, todos ellos, como puede apreciarse, referidos a acciones formativas centradas en el principio de la igualdad de género, cada uno, a diferente nivel.

Acción Formativa 1: Integración del principio de igualdad de género en la planificación y el presupuesto, dirigida a personal de los diferentes Centros Directivos y Delegaciones Provinciales de la Consejería, así como a técnicos y directivos de la red de centros y servicios del Sistema para la Autonomía y Atención a la Dependencia que desarrolle tareas relativas a planificación, gestión y evaluación de programas presupuestarios.

Acción Formativa 2: Integración de la igualdad de género en la valoración de la situación de dependencia, dirigida a profesionales técnicos adscritos a los Servicios de Valoración de las Delegaciones Provinciales de la Consejería encargados de administrar el Baremo de Valoración de la situación de Dependencia

Acción Formativa 3: Integración de la perspectiva de género en la elaboración del Programa Individual de Atención (PIA), dirigida a profesionales de los Servicios Sociales Comunitarios encargados de elaborar la propuesta del Programa Individual de Atención, así como a los de los Servicios de Acción e Inserción Social de las distintas Delegaciones de la Consejería de Igualdad y Bienestar Social encargados de la resolución de la propuesta de PIA. 
También hallamos otro plan de formación dirigido, esta vez, no a profesionales del ámbito de la acción social, sino a "cuidadores" en el entorno familiar de personas en situación de dependencia".

Se plantea que, el perfil específico de las personas cuidadoras, así como la dificultad inherente a su labor, que impide disponer de tiempo, ha exigido el diseño de acciones formativas variadas y flexibles para poder atender al mayor número de cuidadores, dado el importante papel que desempeñan. Desde esta perspectiva, el plan de formación contempla dos tipos de acciones formativas "Cuidabús" y "Talleres de formación presenciales dirigido a personas cuidadoras".

Los objetivos generales y específicos de una y otra acción formativa se muestran en la columna de la izquierda de la tabla 4, las dos restantes representan las dos acciones formativas mencionadas.

Comparados los objetivos de ambos programas, a pesar de la fuerte relación entre ellos, no hallamos demasiadas coincidencias. Advertimos que en el primero (Cuidabús) predomina la preocupación por hacer llegar, facilitar, acercar la formación a los cuidadores, centrándose fundamentalmente en los medios que lo hagan posible. Igualmente se advierte una mayor sensibilidad, consideración y reconocimiento por el esfuerzo que supone la labor de cuidador informal. Por el contrario, el segundo (Taller) parece estar más centrado en el bienestar de la persona dependiente. Entendemos que sería bueno reunir las ideas esenciales presentes en ambos y ofrecer una propuesta formativa integral.

Tabla 4. Plan de Formación: El cuidado en el Entorno Familiar de Personas en Situación de Dependencia

\begin{tabular}{|l|c|c|}
\hline \multicolumn{1}{|c|}{ OBJETIVOS } & Cuidabús & Taller \\
\hline $\begin{array}{l}\text { General: Formar e informar a los cuidadores para mejorar la atención a las personas } \\
\text { dependientes aportando técnicas y estrategias básicas que mejoren la calidad de vida y el } \\
\text { contexto socio-familiar de ambos }\end{array}$ & $\mathrm{X}$ & $\mathrm{X}$ \\
\hline Específicos: & & \\
\hline Facilitar el acceso a la información y formación a los cuidadores de personas dependientes & $\mathrm{X}$ & \\
\hline Acercar la formación e información al mayor número de personas cuidadoras & $\mathrm{X}$ & \\
\hline $\begin{array}{l}\text { Aumentar la sensibilización social sobre la situación de dependencia y el papel destacado } \\
\text { de la persona cuidadora. }\end{array}$ & $\mathrm{X}$ & $\mathrm{X}$ \\
\hline Reforzar el mensaje de autocuidado en la persona cuidadora. & $\mathrm{X}$ & \\
\hline Ofrecer formación básica sobre aspectos prácticos del cuidado de personas dependientes & $\mathrm{X}$ & \\
\hline Compensar la escasez de formación con uso de material didáctico complementario & $\mathrm{X}$ & \\
\hline $\begin{array}{l}\text { Ofrecer lugar de encuentro e intercambio de experiencias a las personas que se encargan } \\
\text { del cuidado de algún familiar en situación de dependencia. }\end{array}$ & $\mathrm{X}$ & \\
\hline $\begin{array}{l}\text { Facilitar conocimiento global de funciones, habilidades y aptitudes necesarias para } \\
\text { desempeñar la labor cuidadora. }\end{array}$ & & $\mathrm{X}$ \\
\hline $\begin{array}{l}\text { Informar sobre hábitos saludables en las personas dependientes para potenciar su } \\
\text { bienestar físico e intelectual. }\end{array}$ & & $\mathrm{X}$ \\
\hline Mejorar la calidad en la atención a las personas en situación de dependencia. & $\mathrm{X}$ \\
\hline Mejorar la calidad de vida de la persona dependiente y de la que le atiende. & $\mathrm{X}$ \\
\hline $\begin{array}{l}\text { Proporcionar herramientas y estrategias para que la relación interpersonal entre persona } \\
\text { dependiente-cuidadora sea positiva, enriquecedora y saludable }\end{array}$ & $\mathrm{X}$ \\
\hline Fortalecer los valores sociales de solidaridad intergeneracional. & $\mathrm{X}$ \\
\hline $\begin{array}{l}\text { Contribuir a disminuir el estrés del cuidador mejorando su situación psicológico-emocional } \\
\text { y de su familia. }\end{array}$ & & $\mathrm{X}$ \\
\hline $\begin{array}{l}\text { Facilitar herramientas para conciliar la labor de cuidador informal con la vida personal, } \\
\text { familiar y social. }\end{array}$ & $\mathrm{X}$ \\
\hline
\end{tabular}

La revisión de los documentos analizados, no nos deja claro quienes habrán sido los profesionales que hayan abordado la labor de diseño y planificación de tales planes de formación. Entendiendo que dicha labor representa una función netamente pedagógica, suponemos que los profesionales pedagogos hayan podido tener un elevado protagonismo, no obstante, consideramos conveniente averiguar qué peso han tenido sus contribuciones, en qué han consistido, etc. para poder actuar en consecuencia, en la misión de formación que nos ocupa. 


\section{Conclusiones}

Existen acciones, programas, recursos, etc. en el ámbito de la acción social dirigidos a la protección social y al desarrollo, que en la actualidad no han sido considerados en nuestro programa formativo de prácticas externas curriculares como opciones posibles de intervención de nuestros estudiantes, haciéndose necesario abordar su estudio en profundidad y ofrecerlos como contextos de formación.

Para llegar a diseñar, planificar y desarrollar opciones formativas enriquecedoras para nuestros estudiantes, a la vez que resulten de utilidad para los centros y entidades de prácticas externas, se hace preciso establecer relaciones estrechas de cooperación y coordinación entre Universidad y Comunidad para estudiar modos de colaboración e intercambio mediante fórmulas de aprendizaje-servicio.

Una buena formación de los futuros profesionales que desarrollen su actividad en contextos de acción social, entendemos que es la mayor y mejor garantía del progreso en el desarrollo social y ello, exige como paso previo, conocer las diferentes opciones y modalidades profesionales, así como las singularidades de cada uno de los contextos de prácticas.

Se advierte la conveniencia de clarificar las atribuciones de los profesionales (funciones, tareas, competencias, etc.) que venimos estudiando para que, delimitando su campo de actuación, podamos reivindicar aquellos campos que le son propios atendiendo a la especificidad que su desempeño profesional.

\section{Referencias}

Corbin, J. (2010). La investigación en la teoría fundamentada como medio para generar conocimiento profesional. En S. Bérnard (Coord.). La teoría fundamentada: una metodología cualitativa (pp. 1354). México: UAA.

Fung, M.Y. (2005). A Philosophy of Teaching Practicum: Construction of a Personal Theory of Teaching and Learning. Teacher Development, 9(1), 43.

Glaser, B. \& Strauss, A. (1967). The discovery of grounded theory: strategies for qualitative research (pp.101-115). New York: Aldine Publishing Company.

Global University Network for Innovation (2009), La Educación Superior en Tiempos de Cambio: Nuevas Dinámicas para la Responsabilidad Social. Madrid: Mundi-Prensa.

Grootenboer, P. (2006). The Impact of the School-Based Practicum on Pre-Service Teachers' Affective Development in Mathematics. Mathematics Teacher Education and Development, 7, 18.

Junta de Andalucia (1997). Acuerdo de 26 de diciembre de 1996, del Consejo de Gobierno, por el que se aprueba el Plan Integral para la Comunidad Gitana de Andalucía. Consejería de Asuntos Sociales. BOJA número 22 de 20 de febrero.

Junta de Andalucia (2005a). Orden de 13 de julio de 2005, por la que se aprueba el Proyecto Educativo Marco para los centros de protección de menores en el ámbito de la Comunidad Autónoma de Andalucía. BOJA número 150 de 3 de agosto.

Junta de Andalucía (2005b). Corrección de errores a la Orden de 13 de julio de 2005, por la que se aprueba el Proyecto Educativo Marco para los centros de protección de menores en el ámbito de la Comunidad Autónoma de Andalucía. BOJA número 189 de 27 de septiembre).

Junta de Andalucía (2006). Decreto 92/2006, de 9 de mayo por el que se aprueba el Il Plan Integral para la Inmigración en Andalucía. BOJA número 105 de 2 de junio. 
Junta de Andalucia (2007). 2 Plan Integral para la Inmigración en Andalucía 2006-2009. Sevilla: Consejería de Gobernación.

Junta de Andalucía (2009a). Ley 1/2009, de 27 de febrero, reguladora de la Mediación Familiar en la Comunidad Autónoma de Andalucía. BOE número 80 de 2 de abril

Junta de Andalucía (2009b). Ley 1/2009, de 27 de febrero, reguladora de la Mediación Familiar en la Comunidad Autónoma de Andalucía. BOJA número 50 de 13 de marzo.

Junta de Andalucía (2010). Decreto 327/2010, de 13 de julio, por el que se aprueba el Reglamento Orgánico de los Institutos de Educación Secundaria. BOJA número 139 de 16 de julio.

Junta de Andalucía (2012). Decreto 37/2012, de 21 de febrero, por el que se aprueba el Reglamento de Desarrollo de la Ley 1/2009, de 27 de febrero, reguladora de la Mediación Familiar en la Comunidad Autónoma de Andalucía. BOJA número 46 de 7 de marzo.

Junta de Andalucía (2014). Decreto 124/2014, de 2 de septiembre, por el que se aprueba el III Plan Integral para la Inmigración en Andalucía Horizonte 2016. BOJA número 172 de 4 de septiembre.

Junta de Andalucia (2015a) Decreto de la Presidenta 12/2015, de 17 de junio, de la Vicepresidencia y sobre reestructuración de Consejerías. BOJA número 117 de 18 de junio.

Junta de Andalucia (2015b). Nuevo Plan Estratégico para la Integración de la Comunidad Gitana de Andalucía 2015-2010. Recuperado de: http://www.juntadeandalucia.es/organismos/igualdadypoliticassociales/areas/inclusion/comunidadgitana/paginas/picga.html

Junta de Andalucía (2015c). Servicios Sociales Comunitarios. Recuperado de: http://www.juntadeandalucia.es/organismos/igualdadypoliticassociales/areas/inclusion/servicioscomunitarios.html

Junta de Andalucía (2015d). El área de voluntariado social. Recuperado de: http://www.juntadeandalucia.es/organismos/igualdadypoliticassociales/areas/inclusion/voluntariado -social/paginas/area-voluntariado.html

Junta de Andalucía (2015e) Zonas de Transformación Social. Recuperado de: http://www.juntadeandalucia.es/organismos/igualdadypoliticassociales/areas/inclusion/zonastransformacion.html.

Junta de Andalucía (2015f). Drogodependencia. Recuperado de: http://www.juntadeandalucia.es/organismos/igualdadypoliticassociales/areas/drogodependencia.ht $\mathrm{ml}$

Junta de Andalucia $(2015 \mathrm{~g})$. Personas Mayores. Recuperado de: http://www.juntadeandalucia.es/organismos/igualdadypoliticassociales/areas/mayores/presentacion .html

Junta de Andalucía (2015h). Infancia y Familias. Recuperado de: http://www.juntadeandalucia.es/organismos/igualdadypoliticassociales/areas/infancia-familias.html.

Junta de Andalucía (2015i). Apoyo a la familia. Recuperado de: http://www.juntadeandalucia.es/organismos/igualdadypoliticassociales/areas/infanciafamilias/apoyo-familias.html.

Junta de Andalucía (2015j) Personas con Discapacidad. Recuperado de: http://www.juntadeandalucia.es/organismos/igualdadypoliticassociales/areas/discapacidad.html.

Junta de Andalucía (2015j). Adopción Nacional. Recuperado de: 
Modalidades de actuación de los profesionales de la educación en el campo de lo social

http://www.juntadeandalucia.es/organismos/igualdadypoliticassociales/areas/infanciafamilias/adopcion-nacional.html.

Kay, T.S \& Rangel, D.K. (2009). National Depression Screening Day: An Undergraduate Practicum Experience. Teaching of Psychology, 36(2), 126.

Kelley, K.S., Hart, S. \& King, J.R. (2007). Negotiating Pedagogy Development: Learning to Teach Writing in a Service-Learning Context. Action in Teacher Education, 29(2), 94.

Kerlinger, F.N. (2001)(4). Investigación del comportamiento:[métodos de investigación en ciencias sociales]. México: McGraw-Hill.

Krippendorf, P. (1990). Metodología de análisis de contenido. Teoría y práctica. Barcelona: Paidós.

Sandín, M.P. (2003). Investigación cualitativa en educación: fundamentos y tradiciones. Madrid: McGraw-Hill.

Vickers, M., Harris, C. \& McCarthy, F. (2004). University-Community Engagement: Exploring ServiceLearning Options within the Practicum. Asia Pacific Journal of Teacher Education, 32(2), 129.

Wetig, S. (2006). Social Studies Methods Students Engaged in Service-Learning: Reciprocity Is the Key. Educational Considerations, 34(1), 32.

Zeichner, K. (2010). Nuevas epistemologías en formación del profesorado. Repensando las conexiones entre las asignaturas del campus y las experiencias de prácticas en la formación del profesorado en la universidad. Revista Interuniversitaria de Formación del Profesorado, 68 (24,2), 123-149.

Fecha de recepción / Received: 15/06/2015

Fecha de aceptación / Accepted: 30/06/2015 